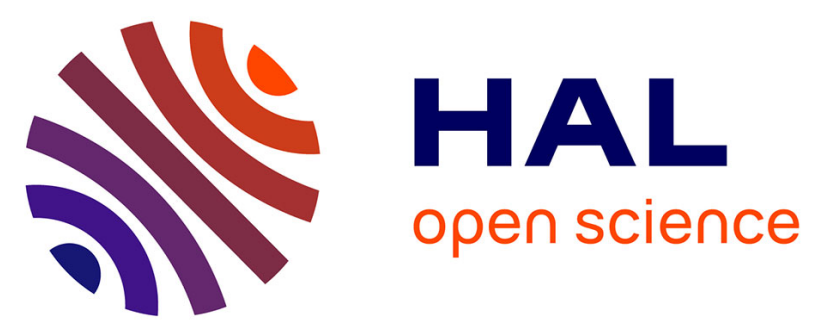

\title{
Study of the natural convection phenomena inside a wall solar chimney with one wall adiabatic and one wall under a heat flux
}

\author{
Evangellos Bacharoudis, Michalis Gr. Vrachopoulos, Maria K. Koukou, \\ Dionysios Margaris, Andronikos E. Filios, Stamatis A. Mavrommatis
}

\section{To cite this version:}

Evangellos Bacharoudis, Michalis Gr. Vrachopoulos, Maria K. Koukou, Dionysios Margaris, Andronikos E. Filios, et al.. Study of the natural convection phenomena inside a wall solar chimney with one wall adiabatic and one wall under a heat flux. Applied Thermal Engineering, 2007, 27 (13), pp.2266. 10.1016/j.applthermaleng.2007.01.021 . hal-00498946

\section{HAL Id: hal-00498946 https://hal.science/hal-00498946}

Submitted on 9 Jul 2010

HAL is a multi-disciplinary open access archive for the deposit and dissemination of scientific research documents, whether they are published or not. The documents may come from teaching and research institutions in France or abroad, or from public or private research centers.
L'archive ouverte pluridisciplinaire HAL, est destinée au dépôt et à la diffusion de documents scientifiques de niveau recherche, publiés ou non, émanant des établissements d'enseignement et de recherche français ou étrangers, des laboratoires publics ou privés. 


\section{Accepted Manuscript}

Study of the natural convection phenomena inside a wall solar chimney with one wall adiabatic and one wall under a heat flux

Evangellos Bacharoudis, Michalis Gr. Vrachopoulos, Maria K. Koukou, Dionysios Margaris, Andronikos E. Filios, Stamatis A. Mavrommatis

PII:

S1359-4311(07)00053-1

DOI:

10.1016/j.applthermaleng.2007.01.021

Reference:

ATE 2083

\section{APPLIED}

THERMAL

ENGINEERING

To appear in:

Applied Thermal Engineering

Received Date: $\quad 14$ September 2006

Revised Date: $\quad 12$ January 2007

Accepted Date: $\quad 16$ January 2007

Please cite this article as: E. Bacharoudis, M.G. Vrachopoulos, M.K. Koukou, D. Margaris, A.E. Filios, S.A. Mavrommatis, Study of the natural convection phenomena inside a wall solar chimney with one wall adiabatic and one wall under a heat flux, Applied Thermal Engineering (2007), doi: 10.1016/j.applthermaleng.2007.01.021

This is a PDF file of an unedited manuscript that has been accepted for publication. As a service to our customers we are providing this early version of the manuscript. The manuscript will undergo copyediting, typesetting, and review of the resulting proof before it is published in its final form. Please note that during the production process errors may be discovered which could affect the content, and all legal disclaimers that apply to the journal pertain. 


\title{
Study of the natural convection phenomena inside a
}

\section{wall solar chimney with one wall adiabatic and one}

\section{wall under a heat flux}

\author{
Evangellos Bacharoudis ${ }^{1}$, Michalis Gr. Vrachopoulos ${ }^{2 *}$, Maria K. Koukou ${ }^{2}$, \\ Dionysios Margaris ${ }^{1}$, Andronikos E. Filios ${ }^{2}$, Stamatis A. Mavrommatis ${ }^{2}$ \\ ${ }^{1}$ University of Patras, Department of Mechanical Engineering \& Aeronautics, Division \\ of Energy, Aeronautics \& Environment, Patras, Greece \\ ${ }^{2 *}$ Technological Educational Institution of Chalkida, Mechanical Engineering \\ Department, Environmental Research Laboratory, 34400 Psachna, Evia, Greece
}

\section{Abstract}

Four wall solar chimneys have been constructed and put at each wall and orientation of a small-scale test room so as to be used for the evaluation and measurement of their thermal behavior and the certification of their efficiency. At this stage, research focuses on the study of the buoyancy-driven flow field and heat transfer inside them. A numerical investigation of the thermo-fluid phenomena that take place inside the wall solar chimneys is performed and the governing elliptic equations are solved in a twodimensional domain using a control volume method. The flow is turbulent and six different turbulence models have been tested to this study. As the realizable k- $\varepsilon$ model is likely to provide superior performance for flows boundary layers under strong adverse pressure gradients, it has been selected to be used in the simulations. This is also 
confirmed by comparing with the experimental results. Predicted velocity and temperature profiles are presented for different locations, near the inlet, at different heights and near the outlet of the channel and they are as expected by theory. Important parameters such as average Nusselt number are also compared and calculated at several grid resolutions. The developed model is general and it can be easily customised to describe various solar chimney's conditions, aspect ratios, etc. The results from the application of the model will support the effective set-up of the next configurations of the system.

Keywords: wall solar chimney, heat transfer, buoyancy, simulation, experiment

Corresponding Author: Prof. M. Gr. Vrachopoulos, mvrachop@teihal.gr, +30 2228099661, +30 6976766791, fax +302228099660

\section{Nomenclature}

B Inter-plate spacing in the channel (m)

g Gravitational acceleration $\left(\mathrm{m} / \mathrm{s}^{2}\right)$

Gr Grashof number

$\mathrm{h}$ Heat transfer coefficient $\left(\mathrm{W} / \mathrm{m}^{2}-\mathrm{K}\right)$, in Eqs.4,5

$\mathrm{k}$ Thermal conductivity (W/m-K)

L Streamwise length of channel (m)

$\dot{m} \quad$ Mass flow rate $(\mathrm{kg} / \mathrm{s})$

$\mathrm{Nu} \quad$ Average Nusselt number, in Eqs.4,5

$\mathrm{p} \quad$ Static pressure at inlet region $(\mathrm{Pa})$

$\mathrm{p}_{\mathrm{a}} \quad$ Ambient pressure $(\mathrm{Pa})$

$p^{\prime} \quad$ Reduced pressure $(\mathrm{Pa}) p^{\prime}=p-p_{o}$

Pr Prandtl number 
q Heat flux from channel's walls $\left(\mathrm{W} / \mathrm{m}^{2}\right)$, in Eqs.4,5

Ra Rayleigh number, in Eqs.1,2

$R a^{*} \quad$ Modified Rayleigh number, in Eq.3

$\mathrm{S}_{\mathrm{u}}, \mathrm{S}_{\mathrm{v}} \quad$ Source terms in momentum Eqs. 7,8

$S_{\varphi} \quad$ Source term in scalar Eq. 9

$\mathrm{T}_{\mathrm{w} 1} \quad$ Temperature of left wall in Eqs. 1,2 (K)

$\mathrm{T}_{\mathrm{w} 2} \quad$ Temperature of right wall in Eqs. 1,2 (K)

$\mathrm{T}_{\mathrm{o}} \quad$ Ambient temperature (K)

$\mathrm{u}, \mathrm{v} \quad$ Velocity components in the $\mathrm{x}$ and $\mathrm{y}$ direction $(\mathrm{m} / \mathrm{s})$

Greeks

$\beta \quad$ Coefficient of thermal expansion, $1 / T_{o}(1 / \mathrm{K})$

$\Gamma_{\varphi} \quad$ Exchange coefficient for general transport fluid scalar $(\mathrm{kg} / \mathrm{m}-\mathrm{s})$

$\mu \quad$ Dynamic viscosity $(\mathrm{kg} / \mathrm{ms})$

$v \quad$ Kinematic viscosity $\left(\mathrm{m}^{2} / \mathrm{s}\right)$

$\rho \quad$ Density $\left(\mathrm{kg} / \mathrm{m}^{3}\right)$

$\varphi \quad$ General transport fluid scalar

\section{Subscripts}

b

Based on inter-plate spacing

L Based on streamwise length of channel

$1 \quad$ Left wall

o Ambient conditions

r Right wall 


\section{Introduction}

In Mediteranean countries, solar radiation during summer months is very intense and the ambient air temperature often rises up to $40^{\circ} \mathrm{C}$ or above. This fact in combination with the limitations of conventional energy sources, in terms of cost and availability, and the increased awareness of environmental issues, have led to renewed interest in passive building design. Passive solar heating, in which part or all of the building is a solar collector, has been widely examined, passive solar cooling, however, remains largely unexplored. Among the applications of these technologies, particularly appropriate for the hot-humid climates of Mediteranean region is solar chimney which is an effective technique to reduce the temperature inside a building as well as to provide natural ventilation, which helps in lowering the humidity and achieving comfortable conditions inside the space. A solar chimney generates air movement by buoyancy forces, in which hot air rises and exits from the top of the chimney, drawing cooler air through the building in continuous cycle. Its application in buildings may provide the required ventilation while simultaneously covers part of the heating and cooling requirements. The thermally-induced air flow depends on the difference in air density between the inside and outside of the solar chimney. In the ways to increase the solar heat absorption and ventilation rate, the replacement of the south-facing wall of the solar

chimney with glazing, the blackening of the interior of other walls and the insulation of the exterior can be considered.

Solar chimneys have been investigated by a number of researchers and for different applications including passive solar heating and cooling of buildings, ventilation, power generation, etc. [1-8]. Experimental and theoretical studies have been conducted for the 
determination of the size of a solar chimney, confirming that the velocity of air flow and temperature of different parts are functions of the gap between absorber and walls, ambient air temperature, and the elevation of air exit above the inlet duct.

Although the behaviour of solar chimneys in their general form has been studied and certified both theoretically and experimentally [1-8], however, the wall solar chimney concept has been studied theoretically but it has not been fully certified at a laboratory level [9-10]. AboulNaga and Abdrabboh [9] made a theoretical investigation of a combined wall roof solar chimney to improve night time ventilation in buildings. They have developed a spreadsheet computer program for the parametric study to find out the optimum configuration of the wall roof chimney. Chantawong et al [10] made an experimental and numerical study of the thermal performance of a glazed solar chimney wall (GSCW). Experimental results conducted using a labscale GSCW $0.74 \mathrm{~m}$ high and $10 \mathrm{~cm}$ air gap were in good agreement with those obtained by solving the heat transfer equations using an explicit finite-difference scheme and Gauss Seidel iterative method.

The wall solar chimneys are embodied in the building cell, they consist of integral parts and they do not modify the architectural view of the building in contrast with the classic "solar chimneys" that have a quite much larger width and contain quite larger air mass. Their operation induces the natural draw which causes the required under pressure in the area so as to be filled with fresh air e.g. from an underground and cooler place. This under pressure causes air uptake conditions from other places having higher pressure (atmospheric) and such kind of places are the underground places which are in lower temperature conditions in comparison with the outside environment and with the places that will be air conditioned (the average temperature of underground places is equal to the average annual air temperature in an area and in Athens is equal to $19^{\circ} \mathrm{C}$ 
which causes the cooling of a place that has conditioning requirements of $26^{\circ} \mathrm{C}$ ). This results in both the coverage of the air replenishment loads and (from the other side to) the qualitative replenishment of the air in the place. The wall solar chimneys are channels with quite high air velocity and intensity of natural draw inducing such conditions that it is required to perform a detailed thermo-fluid analysis. To meet this objective experimental and theoretical work has been scheduled so as to obtain a clear understanding of the system's operation.

Research work will be carried out through various stages assuming different configurations with various degree of complexity. At this current first stage, the air from the outside space enters the solar chimney from the bottom and escapes from the top and there is no connection with the room's interior. With this configuration research focuses on the flow field and temperature variation inside the wall solar chimney so as to understand the system behavior under various environmental conditions. At a second stage, various configurations will be applied where air will flow from or to the room interior through openings at the walls. With these configurations it is scheduled to study the solar chimney's performance focusing on the system capability to decrease temperature at the room interior providing thermal comfort as well as on room ventilation either with air uptake or with air recycling.

In the present study, a numerical investigation of the thermo-fluid phenomena that take place inside the wall solar chimneys is performed. The developed model faces the problem as a natural convection one between two vertical parallel plates and the governing elliptic equations are solved in a two-dimensional domain using a control volume method. It accounts for a detailed thermo-fluid analysis in contrast with the models proposed in other works which are quite simpler $[9,10]$. Furthermore, as the 
flow conditions inside the wall solar chimneys studied in this work are in the turbulence regime special focus is given in the correct description of turbulence and various turbulence models are tested. In the wall solar chimneys studied the air channel has very small width and the surface of solar incidence is much larger in comparison with that of solar chimneys of older type [2-6]. This causes the thermal intension of the air content and the development of higher velocities and turbulent flow conditions in contrast with the conventional (of older type) solar chimneys where the thermal intension of the air content is lower, air velocity values are much smaller and velocity profiles are quite different.

Predicted velocity and temperature profiles together with the average Nusselt number are presented for different locations, near the inlet, at different heights and near the outlet of the channel. The procedure is general and can be applied for the simulation of solar chimneys of different aspect ratios and conditions. First results show that the model predicts realistically the system behaviour for various environmental conditions. Next steps focus on the extended verification of the current version of the model with experimental results and on the modification of the model to study the configurations where air will flow from or to the room interior through openings at the walls.

\section{The physical problem}

\subsection{Experimental facility}

A model room has been designed and constructed at the campus of the Technological Educational Institution of Chalkida located in the agricultural area of Psachna. The dimensions of the room are $4 \mathrm{~m} \times 6 \mathrm{~m} \times 4 \mathrm{~m}$ and its roof is covered with roman tiles and a radiant barrier reflective insulation system (Fig. 1a). Four wall solar chimneys have been 
constructed and put at each wall and orientation (Fig. 1a). In Fig. 1b details on the flow through the wall solar chimney and their construction are shown together with the size of the air gap. The chimneys are constructed from plaster board. At this first stage, the air from the outside space enters the solar chimney from the bottom and escapes from the top and there is no connection with the room's interior. For the measurements in the current configuration of the wall solar chimneys small holes have been opened along the chimney height so as to obtain velocity and temperature measurements close to the inlet, close to the outlet and at the middle of the solar chimneys. Air velocity and temperature at the solar chimneys has been measured with KIMO VT 200 hot wire anemometer.

\subsection{Characteristics of solar chimney}

In Fig. 2 the geometry of the wall solar chimney studied is presented wherein L, is the height of the chimney and $b$, is the inter-plate spacing. The left and right walls are considered isothermal and heat transfer through the walls causes buoyancy-driven flow.

The solution of the governing conservation equations in their dimensionless form depends on the Rayleigh number based either on the channel length, L:

$\mathrm{Ra}_{\mathrm{L}}=\frac{\mathrm{g} \beta\left(\mathrm{T}_{\mathrm{w} 1}-\mathrm{T}_{\mathrm{w} 2}\right) \mathrm{L}^{3}}{v^{2}} \cdot \operatorname{Pr}$

or on the inter-plate spacing, $b$ :

$$
\mathrm{Ra}_{\mathrm{b}}=\frac{\mathrm{g} \beta\left(\mathrm{T}_{\mathrm{w} 1}-\mathrm{T}_{\mathrm{w} 2}\right) \mathrm{b}^{3}}{v^{2}} \cdot \operatorname{Pr}
$$

where $\beta$, is the volumetric thermal expansion coefficient namely the change in the density of air as a function of temperature at constant pressure $\left(\mathrm{K}^{-1}\right), \mathrm{g}$ is the gravitational acceleration $\left(9.81 \mathrm{~m}^{2} / \mathrm{s}\right), v$ is the kinematic viscosity $\left(\mathrm{m}^{2} / \mathrm{s}\right), \mathrm{T}_{\mathrm{w} 1}, \mathrm{~T}_{\mathrm{w} 2}$ are the 
left and right wall temperatures, respectively and Pr, is the Prandtl number.

Traditionally, in such kind of problems the dimensionless form of the equations is based on the channel width/inter plate spacing, $b$ and thus the solution of the equations is a function of $\mathrm{Ra}_{\mathrm{b}}$ and the ratio $\mathrm{b} / \mathrm{L}$.

The modified Rayleigh, $\mathrm{Ra}^{*}$ is also used defined as the ratio of the Rayleigh number to the aspect ratio of the channel:

$\mathrm{Ra}^{*}=\mathrm{Ra}_{\mathrm{b}} \cdot\left(\frac{\mathrm{b}}{\mathrm{L}}\right)(3)$

which is a very useful number for the integrated presentation of the results.

The $\mathrm{Ra}_{\mathrm{L}}$ and more specifically the Grashof number, $\mathrm{Gr}_{\mathrm{L}}$ where $\mathrm{Gr}_{\mathrm{L}}=\mathrm{Ra}_{\mathrm{L}} / \mathrm{Pr}$ is usually used in heat transfer for the definition of the flow regime to be laminar or turbulent. It has the same role with Reynolds number in forced convection flows and it indicates the ratio of the bouyancy force to the viscous force acting on the fluid. The buoyant forces are fighting with viscous forces and at some point they overcome the viscous forces and the flow is no longer laminar. For a vertical plate, the flow transitions to turbulent around a Grashof number of $10^{9}[11,13]$.

In the following, the modified $\mathrm{Ra}_{\mathrm{b}}$ was used for the better presentation of the results and the $\mathrm{Ra}_{\mathrm{L}}$ was used for the definition of the flow regime to be laminar or turbulent.

From the engineering point of view an important characteristic of the flow is the rate of heat transfer through the solar chimney walls. Using Newton's law of cooling for the local convection coefficient $\mathrm{h}$ the Nusselt number for the left and right wall of Fig. 2 may be expressed as: 
- Left wall:

$$
N u_{b l}=\frac{h \cdot b}{k} \quad \text { where } \quad h=\frac{q}{T_{w 1}-T_{o}} \quad \text { and } \quad q=\left.\int \frac{\partial T}{\partial x}\right|_{x=0} d y
$$

$$
N u_{L l}=\frac{h \cdot L}{k}
$$

- Right wall:

$$
N u_{b r}=\frac{h \cdot b}{k} \quad \text { where } \quad h=\frac{q}{T_{o}-T_{w 2}} \quad \text { and } \quad q=\left.\int \frac{\partial T}{\partial x}\right|_{x=0} d y
$$

$$
N u_{L r}=\frac{h \cdot L}{k}
$$

\section{Mathematical modeling of the wall solar chimney}

\subsection{The governing equations}

The computational model of the wall solar chimney is a mathematical representation of the thermo-fluid phenomena governing its operation. A numerical investigation of the natural buoyancy-driven fluid flow and heat transfer in the vertical channel has been attempted. The simulations were conducted using the commercial, well-known, generalpurpose CFD code, Fluent ${ }^{\circledR}$. The steady, laminar, incompressible and two-dimensional form of the conservation equations $[13,14]$ was solved for the fluid flow in the vertical channel using the Boussinesq approximation [15]. The latter imposes constant values in all thermophysical properties except for the density in the buoyancy force term of the momentum equation. It is also assumed that viscous dissipation is neglected.

For steady flow, the equations for continuity, velocity components and temperature take the following form $[13,14]$ :

$$
\begin{array}{ll}
\text { continuity: } & \frac{\partial(\rho \mathrm{u})}{\partial \mathrm{x}}+\frac{\partial(\rho \mathrm{v})}{\partial \mathrm{y}}=0 \\
\text { x-momentum: } & \frac{\partial(\rho \mathrm{uu})}{\partial \mathrm{x}}+\frac{\partial(\rho \mathrm{vu})}{\partial \mathrm{y}}=\frac{\partial}{\partial \mathrm{x}}\left(\mu \frac{\partial \mathrm{u}}{\partial \mathrm{x}}\right)+\frac{\partial}{\partial \mathrm{y}}\left(\mu \frac{\partial \mathrm{u}}{\partial \mathrm{y}}\right)+\mathrm{S}_{\mathrm{u}}
\end{array}
$$


y-momentum: $\quad \frac{\partial(\rho \mathrm{uv})}{\partial \mathrm{x}}+\frac{\partial(\rho \mathrm{vv})}{\partial \mathrm{y}}=\frac{\partial}{\partial \mathrm{x}}\left(\mu \frac{\partial \mathrm{v}}{\partial \mathrm{x}}\right)+\frac{\partial}{\partial \mathrm{y}}\left(\mu \frac{\partial \mathrm{v}}{\partial \mathrm{y}}\right)+\mathrm{S}_{\mathrm{v}}$

general transported

fluid scalar, $\phi$ (e.g. T): $\quad \frac{\partial\left(\rho_{\mathrm{u}} \phi\right)}{\partial \mathrm{x}}+\frac{\partial\left(\rho_{\mathrm{v}} \phi\right)}{\partial \mathrm{y}}=\frac{\partial}{\partial \mathrm{x}}\left(\Gamma_{\phi} \frac{\partial \phi}{\partial \mathrm{x}}\right)+\frac{\partial}{\partial \mathrm{y}}\left(\Gamma_{\phi} \frac{\partial \phi}{\partial \mathrm{y}}\right)+\mathrm{S}_{\phi}$

where: $x, y$ are the coordinates in the Cartesian-coordinate system indicated in Fig. 2, $\rho$, is air's density $\left(\mathrm{kg} \cdot \mathrm{m}^{-3}\right), \mathrm{S}_{\mathrm{u}}, \mathrm{S}_{\mathrm{v}}$, are momentum source terms in the $\mathrm{x}-$, $\mathrm{y}-$, directions, respectively, $\mu$, is air's viscosity, $\Gamma_{\varphi}$ is the exchange coefficient for the general transport fluid scalar $\varphi$.

For $\mathrm{Ra}_{\mathrm{L}}$ above $10^{9}$ a two equation turbulence model should be used. In this context, the above equations become time-averaged equations and $\mu, \Gamma_{\varphi}$ are replaced by their effective values $\mu_{\mathrm{eff}}, \Gamma_{\text {eff }}$ as given by the turbulence model.

\subsection{Boundary and internal conditions}

Boundary conditions must be specified at the inlet, outlet and walls. Details on their specification are given below, for the application considered.

\subsection{Numerical solution details}

The solution of the set of the equations together with the boundary and internal conditions has been made with the segregated steady-state solver embodied in Fluent ${ }^{\circledR}$ commercial software. Because the governing equations are non-linear (and coupled), several iterations of the solution loop must be performed before a converged solution is obtained. SIMPLE method has been used in all cases studied. Because of the nonlinearity of the problem the solution process is controlled via relaxation factors that control the change of the variables as calculated at each iteration. The convergence is 
checked by several criteria (e.g. the conservation equations should be balanced; the residuals of the discretised conservation equations must steadily decrease). Gridindependence studies and computer requirements are presented below, for the application considered.

\section{Application of the model}

\subsection{The case considered}

The wall solar chimney studied in this work is one of the wall solar chimneys of the test room. The values of the height and the inter-plate spacing of the latter solar chimney are $4 \mathrm{~m}, 0.05 \mathrm{~m}$, respectively, and the aspect ratio is equal to $\frac{\mathrm{b}}{\mathrm{L}}=0.0125$. It is assumed that the chimney's walls are isothermal but they have different temperatures $T_{w 1}$ and $T_{w 2}$, respectively. Actually, the left wall temperature varies with time and during the whole day however, it is realistic to assume that it is almost constant for a certain time period of the day. The thermo-fluid analysis performed describes the phenomenon during the above certain period of the day which is not random and it has been selected during noon when the requirements for indoors cooling reach their maximum. Furthermore, the existence of the reflective insulation may justify that way of approach because its thermal behavior causes unknown conditions and thus various approximate methods can be applied.

The working fluid is air $(\operatorname{Pr}=0.713)$ coming into from the bottom of the channel (1) at a constant ambient temperature $T_{0}$ and gets out from the top (Fig. 2). The fluid is motionless at the point 0 in ambient temperature $T_{0}=29.7^{\circ} \mathrm{C}$. The estimated 
$\mathrm{Ra}_{\mathrm{L}}=1.0392 \cdot 10^{11}$ confirms the existence of turbulent flow conditions.

\subsection{Boundary Conditions}

Inlet: At the inlet section, it is obvious that there is a specific velocity profile because the fluid is moving with a specific mass flow rate. It is well-known that this velocity profile is the result of the pressure difference between two points inside and outside of the channel at the same height. Let us consider the points 0,1 in Fig. 2. The fluid is motionless at the point 0 in ambient temperature $T_{0}=20^{\circ} \mathrm{C}$ and static pressure $p_{0}$. In point 1 the fluid obtains an unknown velocity profile which produces mass flow rate at inlet temperature $T_{o}$ and static pressure p. According to the literature [16-21] it is assumed that the air moves from point 0 to point 1 with an adiabatic and reversible way. Specifically, the Bernoulli equation holds at the entrance region outside the channel and the pressure difference between the two points is converted to kinetic energy. From Fig. 2 (Bernoulli $0 \rightarrow 1$ ):

$$
\begin{aligned}
& \mathrm{p}+\frac{1}{2} \rho \mathrm{u}^{2}=\mathrm{p}_{\mathrm{o}} \Rightarrow \\
& \mathrm{p}-\mathrm{p}_{\mathrm{o}}+\frac{1}{2} \rho \mathrm{u}^{2}=0 \Rightarrow \\
& \mathrm{p}^{\prime}+\frac{1}{2} \rho \mathrm{u}^{2}=0 \Rightarrow \\
& \mathrm{p}^{\prime}=-\frac{1}{2} \rho \mathrm{u}^{2}
\end{aligned}
$$

where: $\mathrm{p}^{\prime}$, is the 'reduced' static pressure and $\mathrm{p}_{\mathrm{o}}$, is the ambient pressure with $\mathrm{p}_{\mathrm{o}}=-\rho_{\mathrm{o}} \mathrm{gy}$. Moreover, it is assumed that the streamwise variations of temperature are neglected.

Furthermore, regarding inlet conditions for turbulence, the turbulence intensity has been assumed equal to $0.01 \%$ which is considered realistic as the fluid flow at the channel 
entrance is laminar and it is developed to the turbulent regime upwards while the length scale is equal to $0.07 \mathrm{D}$ where $\mathrm{D}$, in the general case, is the channel diameter.

\section{Outlet:}

At the outlet section the streamwise variations of velocity components and temperature are neglected. In addition, it is assumed that the fluid's pressure becomes equal to the ambient pressure [16-21]. It is well-known that static pressure in an arbitrary point can be written as: $\begin{aligned} & \mathrm{p}=\mathrm{p}^{\prime}+\mathrm{p}_{\mathrm{o}} \Rightarrow \\ & \mathrm{p}=\mathrm{p}^{\prime}-\rho_{\mathrm{o}} g \mathrm{y}\end{aligned}$

In order to be satisfied the preceding condition $\mathrm{p}=\mathrm{p}_{\mathrm{o}}$ at the outlet region, it is necessary to impose $p^{\prime}=0$. In this way according to Gadafalch et al [18] all the kinetic energy of the air is assumed to be converted to heat.

Finally, it is considered a Backflow Total Temperature $=29.7^{\circ} \mathrm{C}$ in case the fluid entered to the chimney from the outlet. In this case, the incoming air is considered to be fresh air in a temperature $\mathrm{T}_{0}=29.7^{\circ} \mathrm{C}$.

Walls: It is assumed that the walls of the chimney have different temperatures. In the simulations for the left wall the following temperature values have been applied: $\mathrm{T}_{\mathrm{w} 1}=45^{\circ} \mathrm{C}, 50^{\circ} \mathrm{C}, 55^{\circ} \mathrm{C}, 60^{\circ} \mathrm{C}, 65^{\circ} \mathrm{C}, 70^{\circ} \mathrm{C}$. In all cases studied the right wall temperature was equal to $\mathrm{T}_{\mathrm{w} 2}=27^{\circ} \mathrm{C}$.

Furthermore, there are two approaches for modelling the near-wall region. In the first approach, the viscosity-affected inner region is not resolved. Instead a wall function is used to bridge the viscosity-affected region with the fully turbulent region. In the second approach, the turbulence model is modified to enable the viscosity-affected region to be resolved with a mesh all the way to the wall (enhanced wall treatment). If the near-wall mesh is fine enough to be able to resolve the laminar sublayer, then the enhanced wall 
treatment will be identical to the traditional two-layer zonal model. Because of the nature of the buoyancy-induced flow inside the wall solar chimney where special treatment should applied at the near wall region to account for the development of the boundary layers, it has been decided to follow the second approach in the simulations.

\subsection{Grid independence study}

A structure, mapped mesh with quadrilateral $2 \mathrm{D}$ elements has been built in the code. In order to ensure the accuracy of the numerical results, a grid independence study was performed by changing the number of the nodes in the horizontal $(\mathrm{H})$ and in the vertical (V) direction (Table 1). As the flow was in the turbulent regime a thorough investigation has been attempted for each turbulence model applied. Successful computation of turbulent flow requires some consideration during the mesh generation. Due to the strong interaction of the mean flow and turbulence, the numerical results for turbulent flows tend to be more susceptible to grid dependency than those for laminar flows. In all the simulations $\mathrm{y}^{+}<1$ and it has been concluded that a grid consisting of $70 \times 420$ cells can provide sufficient spatial resolution giving a grid-independent solution for each of the turbulence models tested.

\subsection{Turbulence modelling}

For the numerical simulation of the turbulent flow inside the wall solar chimney six turbulence models have been tested provided by Fluent ${ }^{\circledR}$ : the standard k- $\varepsilon$ model, the RNG k- $\varepsilon$ model, the realizable k- $\varepsilon$ model, the Reynolds stress model (RSM), and two Low-Reynolds (Low-Re) models, namely, the Abid and the Lam-Bremhost. The standard two-equation $\mathrm{k}-\varepsilon$ turbulence model involves the solution of two additional 
partial differential equations for the turbulent kinetic energy $(\mathrm{k})$ and its dissipation rate (ع) [22]. The values of the constants $\mathrm{C}_{\mu}, \mathrm{C}_{1}, \mathrm{C}_{2}, \sigma_{\kappa}$ and $\sigma_{\varepsilon}$ applied are $0.09,1.44,1.92$, 1.0 and 1.3 respectively [22]. The RNG $\mathrm{k}-\varepsilon$ model is essentially a variation of the standard k- $\varepsilon$ model, with the used constants estimated rather through a statistical mechanics approach than from experimental data. The values of the constants $C_{\mu}, C_{1}$ and $\mathrm{C}_{2}$ applied are $0.0845,1.42$ and 1.68 , respectively [23]. For the realizable model the term "realizable" means that the model satisfies certain mathematical constraints on the Reynolds stresses, consistent with the physics of turbulent flows. The realizable k- $\varepsilon$ model contains a new formulation for the turbulent viscosity. Also, a new transport equation for the dissipation rate, $\varepsilon$, has been derived from an exact equation for the transport of the mean-square vorticity fluctuation [24]. The RSM closes the Reynoldsaveraged Navier-Stokes equations by solving transport equations for the Reynolds stresses, together with an equation for the dissipation rate. It also requires additional memory and CPU time due to the increased number of the transport equations for Reynolds stresses. However, to account for the low-Re effects wall damping functions should be used in the $\varepsilon$-equation while the dissipation rate term in the transport equations should be modified to take into account the non-uniformity of turbulence. Finally, as concerns the Low-Re models, they are adequate for low-Re flows and if a very fine grid is used they can take into account the viscous sub-layer. Besides, wall damping functions are used in the equation of viscosity and the $\varepsilon$ equation in both the production and the destruction term of the $\varepsilon$. Wall damping functions ensure that viscous stresses take over from turbulent Reynolds stresses at low Reynolds numbers and in the viscous sub-layer adjacent to solid walls. However, these models have been certified for forced convection flows [25]. 
In Table 2 the average Nusselt number for the various turbulence models used is shown.

In Figures 3-6 typical results from the application of the above turbulence models are shown. In all the cases studied the temperature of the left wall was $\mathrm{T}_{\mathrm{w} 1}=45^{\circ} \mathrm{C}$. In Figures 3a,b the streamwise velocity profile vs inter plate spacing at the outlet and middle of the wall solar chimney for various turbulence models is shown. By applying all the turbulence models except RSM, the predictions show that streamwise velocity increases close to the left wall at the outlet of the chimney which is expected by theory. Also, it is worthwhile mentioning that with the application of the Lam-Bremhost model an unexpected high increase of the velocity close to the left wall at the middle of the solar chimney is predicted (Figure 3b). In Figures 4a,b temperature profile vs inter plate spacing at the outlet and middle of the chimney for various turbulence models is shown. It can be noticed that by applying the RSM model quite different profiles are predicted both at the outlet and middle of the solar chimney (Figure 4a,b) while by applying the Lam-Bremhost model a different temperature profile is predicted at the middle of the solar chimney.

Based on the above, it can be concluded that the use of the k- $\varepsilon$ models and the use of the Abid Low-Re model assures the prediction of realistic velocity and temperature profiles as expected by theory. For the final selection it should be taken into account that the turbulence model should account for both the high and low (close to the chimney's walls) Reynolds areas of the computational domain. The k- $\varepsilon$ model is robust and has reasonable accuracy for a wide range of turbulent flows, however, it is a high-Reynoldsnumber model. The RNG k- $\varepsilon$ provides an analytically-derived differential formula for effective viscosity that accounts for low-Reynolds-number effects. Effective use of this feature does, however, depend on an appropriate treatment of the near-wall region. As 
the Abid Low-Re model has been certified for forced convection flows and the realizable k- $\varepsilon$ model is likely to provide superior performance for flows boundary layers under strong adverse pressure gradients, the latter has been selected to be used in the simulations. Furthermore, this selection is confirmed from the comparison with the preliminary experimental results shown in Table 3 where experimental and predicted average velocity and temperature values for the various turbulence models used the outlet of the wall solar chimney are presented. As it is shown the application of the k- $\varepsilon$ and the realizable $\mathrm{k}-\varepsilon$ models provides realistic predictions of the average velocity and of the temperature as well.

\subsection{Typical results and discussion}

In the following typical results from the performed simulations are presented and discussed. In all the cases studied the realizable $\mathrm{k}-\varepsilon$ model has been used.

In Figures 5,6 the predicted streamwise velocity and temperature profiles at the outlet of the wall solar chimney for various temperatures of the left wall are shown. It is well shown that as the left wall temperature increases the streamwise velocity at the channel increases and it is higher close to the wall with the higher temperature. The temperature profiles are as expected by theory (Figure 6). In Table 4 the predicted mass flow rates and average Nu numbers for the left and right walls of the wall solar chimney vs. left wall temperature are shown. Increase in the left wall temperature causes an increase of the mass flow rate and of the heat transfer in the channel as well.

In Figure 7 the predicted average $\mathrm{Nu}_{\mathrm{bl}}$ number for the left wall vs. modified Rayleigh number, $\mathrm{Ra}^{*}$ is shown. In Figures 8,9 typical predicted streamwise velocity and temperature profiles across the solar chimney height are presented for the case where the left wall temperature is equal to $45^{\circ} \mathrm{C}$. The boundary layer development is well shown in 
both figures. At the inlet, the velocity profile, that has been created because of the pressure difference in the channel, is uniform. As the flow is developed upwards an acceleration close to the left wall is noticed. Furthermore, at the beginning and up to $1 \mathrm{~m}$ height the flow is accelerated, however, at higher heights the profile becomes more uniform. This can be explained if it is considered that in the channel except the bouyancy forces that act on the fluid trying to accelerate it upwards, viscous forces also act opposing to the fluid flow. The contribution of turbulence should also been taken into account. Bouyancy forces play major role close to the wall, however, far from the wall laminar or turbulent shear stresses dominate. Furthermore, bouyancy forces tend to become important as temperature difference between fluid and the channel walls become high. As the fluid rises upwards, it is heated and the latter temperature difference decreases causing flow decelaration. It should be mentioned that similar trends occur in the rest of the performed simulations.

\section{CONCLUSIONS}

In this work research focuses on the study of the thermo-fluid phenomena occurring inside wall solar chimneys that have been constructed and put at each wall and orientation of a small-scale test room. A numerical investigation of the buoyancy-driven flow field and heat transfer that take place inside the wall solar chimneys is performed. The governing elliptic equations are solved in a two-dimensional domain using a control volume method. The procedure is general and can be applied for the simulation of solar chimneys of different aspect ratios and conditions. For the numerical simulation of the turbulent flow inside the wall solar chimney six turbulence models have been tested: the standard k- $\varepsilon$ model, the RNG k- $\varepsilon$ model, the realizable k- $\varepsilon$ model, the Reynolds stress 
model (RSM), and two Low-Reynolds (Low-Re) models, namely, the Abid and the Lam-Bremhost. It is concluded that the use of the k- $\varepsilon$ models and the use of the Abid Low-Re model assures the prediction of realistic velocity and temperature profiles as expected by theory. As the realizable $\mathrm{k}-\varepsilon$ model is likely to provide superior performance for flows boundary layers under strong adverse pressure gradients, the latter has been selected to be used in the simulations. Furthermore, this selection is confirmed from the comparison with the experimental results. Simulation results also show that the model predicts realistically the system behaviour for various environmental conditions while they support the evaluation of the air mass flow rate that can be achieved through this system and the turbulence effects.

\section{ACKNOWLEDGEMENT}

This research work is co-funded by the European Social Fund and National resources (EPEAEK II) Archimedes I. 


\section{REFERENCES}

[1] G.S. Barozzi, M.S.E. Imbabi, E. Nobile, A.C.M. Sousa, Physical and numerical modelling of a solar chimney-based ventilation system for buildings, Build. Environ. 27 (4) 1992 433-445.

[2] N.K. Bansal, R. Mathur, M.S. Bhandari, Solar chimney for enhanced stack ventilation, Build. Environ. 28 (1993) 373-377.

[3] G. Gan, S.B. Riffat, A numerical study of solar chimney for natural ventilation of buildings with heat recovery. Appl. Therm. Eng. 18 (1998) 1171-1187.

[4] C. Afonso, A. Oliveira, Solar chimneys: simulation and experiment, Energ. Buildings 32 (2000) 71-79.

[5] Z.D. Chen, P. Bandopadhayay, J. Halldorsson, C. Byrjalsen, P. Heiselberg, Y. Lic, An experimental investigation of a solar chimney model with uniform wall heat flux, Build. Environ. 38 (2003) 893-906.

[6] K.S. Ong, A mathematical model of a solar chimney, Renew. Energ. 28 (2003) $1047-1060$.

[7] K.S. Ong, C.C. Chow, Performance of solar chimney, Sol. Energy 74 (2003) $1-17$.

[8] J. Khedari, N. Rachapradit, J. Hirunlabh, Field study of performance of solar chimney with air conditioned, Building Energy 28 (2003) 1099-1114.

[9] M.M. AboulNaga, S.N. Abdrabboh, Improving night ventilation into low-rise buildings in hot-arid climates exploring a combined wall-roof solar chimney, Renewable Energy 19 (1-2) (2000) 47-54. 
[10] P. Chantawong, J. Hirunlabh, B. Zeghmati, J. Khedari, S. Teekasap, M.M. Win, Investigation on thermal performance of glazed solar chimney walls, Solar Energy 80 (3) (2006) 288-297.

[11] J.P. Holman, Heat transfer, Fourth Edition, International Student Edition, 1976.

[12] B.R. Bird, W.E. Stewart, E.N. Lightfoot, Transport phenomena, John Wiley \& Sons, Inc., New York, 1960.

[13] S.V. Patankar, Numerical heat transfer and fluid flow, McGraw Hill, New York, 1980.

[14] N.C. Markatos, K.A. Pericleous, Laminar and Turbulent Natural Convection in an Enclosed Cavity, Int. J. Heat Mass Transfer 27 (5) (1984) 755-772.

[15] D.D. Gray, A. Giorgini, The validity of the Boussinesq approximation for liquids and gases, Int. J. Heat and Mass Transfer 19 (1976) 545-551.

[16] F. Marcondes, C.R. Maliska, Treatment of the inlet boundary conditions in natural-convection flows in open-ended channels, Numerical Heat Transfer Part B 35 (1999) 317-345.

[17] A.S. Kaiser, B. Zamora, A. Viedma, Correlation for Nusselt number in natural convection in vertical convergent channels at uniform wall temperature by a numerical investigation, International Journal of Heat and Fluid Flow 25 (2004) 671-682.

[18] J. Gadafalch, A. Oliva, G. Van der Graaf, X. Albets, Natural convection in a large, inclined channel with asymmetric heating and surface radiation, ASME Journal of Heat Transfer 125 (2003) 812-820. 
[19] G. Desrayaud, A. Fichera, Laminar natural convection in a vertical isothermal channel with symmetric surface-mounted rectangular ribs, International Journal of Heat and Fluid Flow 23 (2002) 519-529.

[20] B. Zamora, J. Hernandez, Influence of variable property effects on natural convection flows in asymmetrically-heated vertical channels, International Communications in Heat and Mass Transfer 24 (1997) 1153-1162.

[21] B. Zamora, J. Hernandez, Influence of upstream conduction on the thermally optimum spacing of isothermal, natural convection-cooled vertical plates arrays, International Communications in Heat and Mass Transfer 28 (2001) 201-210.

[22] B.E. Launder, D.B. Spalding, The Numerical Computation of Turbulent Flows, Computer Methods in Applied Mechanics and Engineering 3 (1974) 269-289.

[23] V. Yakhot, S.A. Orszag, Renormalization Group Analysis of Turbulence: I. Basic Theory, Journal of Scientific Computing 1(1) (1986) 1-51.

[24] T.H. Shih, W.W. Liou, A. Shabbir, Z. Yang, J. Zhu, A New - Eddy-Viscosity Model for High Reynolds Number Turbulent Flows - Model Development and Validation, Computers Fluids 24(3) (1995) 227-238.

[25] Fluent ${ }^{\circledR} 6.2$ User's Guide. 


\section{LIST OF FIGURES}

Fig. 1a. View of the in-house developed wall solar chimneys.

Fig. 1b. Air flow through the wall solar chimney and construction details.

Fig. 2. The geometry studied.

Fig. 3a. Streamwise velocity profile vs inter plate spacing at the chimney outlet for various turbulence models.

Fig. 3b. Streamwise velocity profile vs inter plate spacing at the middle of the chimney for various turbulence models.

Fig. 4a. Temperature profile vs inter plate spacing at the outlet of the chimney for various turbulence models.

Fig. 4b. Temperature profile vs inter plate spacing at the middle of the chimney for various turbulence models.

Fig. 5. Predicted streamwise velocity profiles at the outlet of the solar chimney for various temperatures of the left wall.

Fig. 6. Predicted temperature profiles at the outlet of the solar chimney for various temperatures of the left wall.

Fig. 7. Predicted average $\mathrm{Nu}_{\mathrm{bl}}$ number for the left wall vs. Modified Rayleigh number.

Fig. 8. Predicted streamwise velocity profiles across the solar chimney height.

Fig. 9. Predicted temperature profiles across the solar chimney height. 


\section{ACCEPTED MANUSCRIPT}

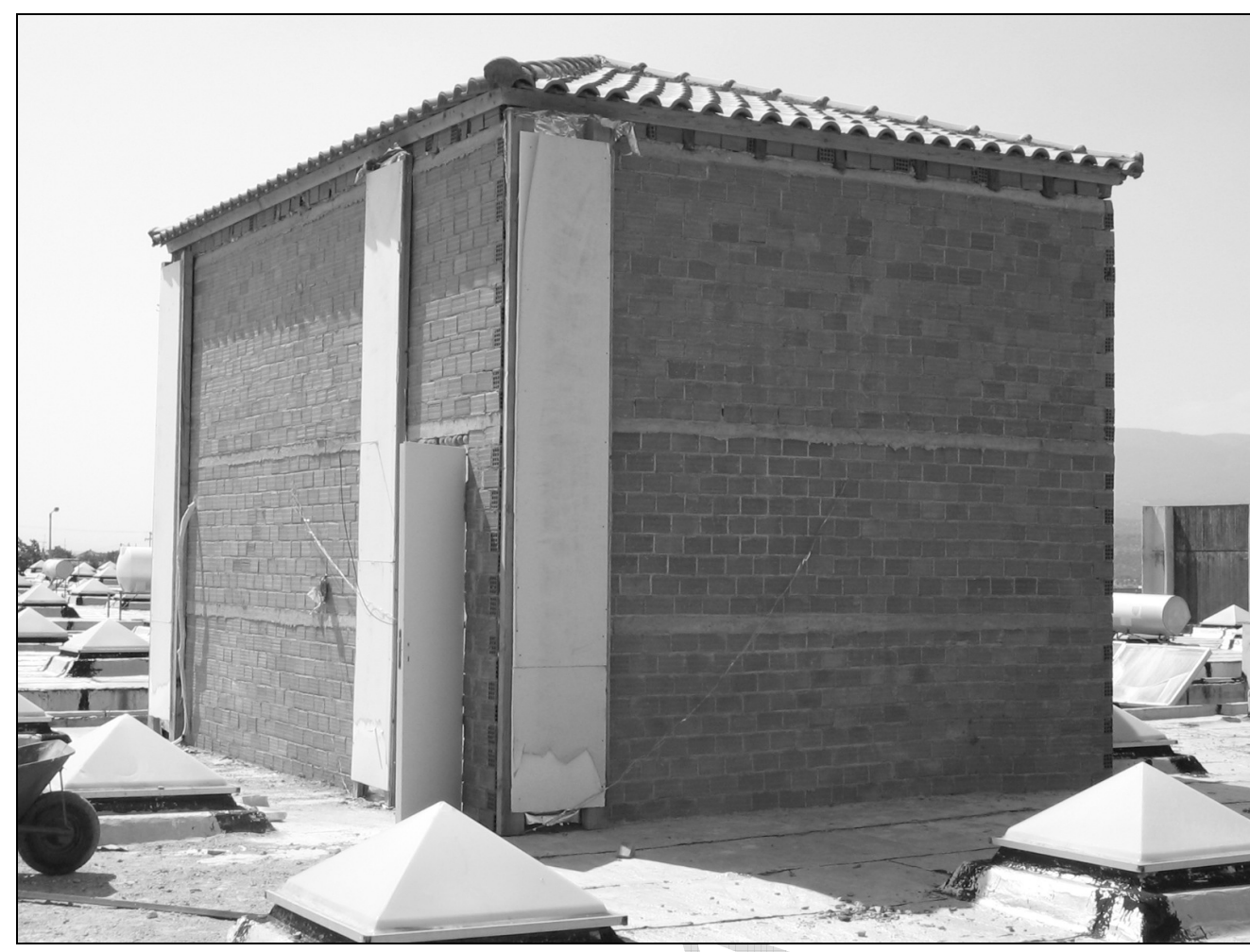

Fig. 1a. View of the in-house developed wall solar chimneys. 


\section{ACCEPTED MANUSCRIPT}

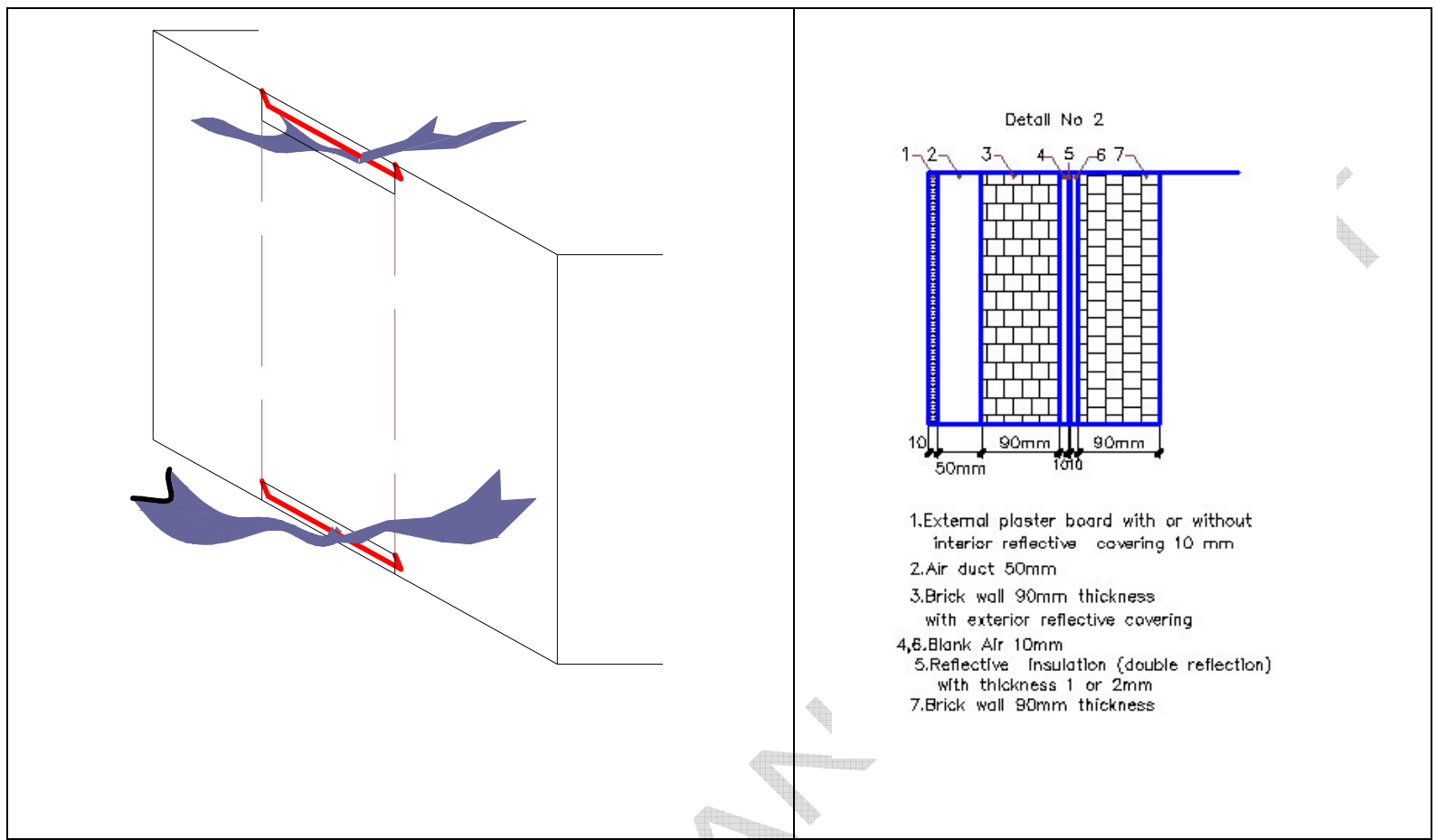

Fig. 1b. Air flow through the wall solar chimney and construction details. 


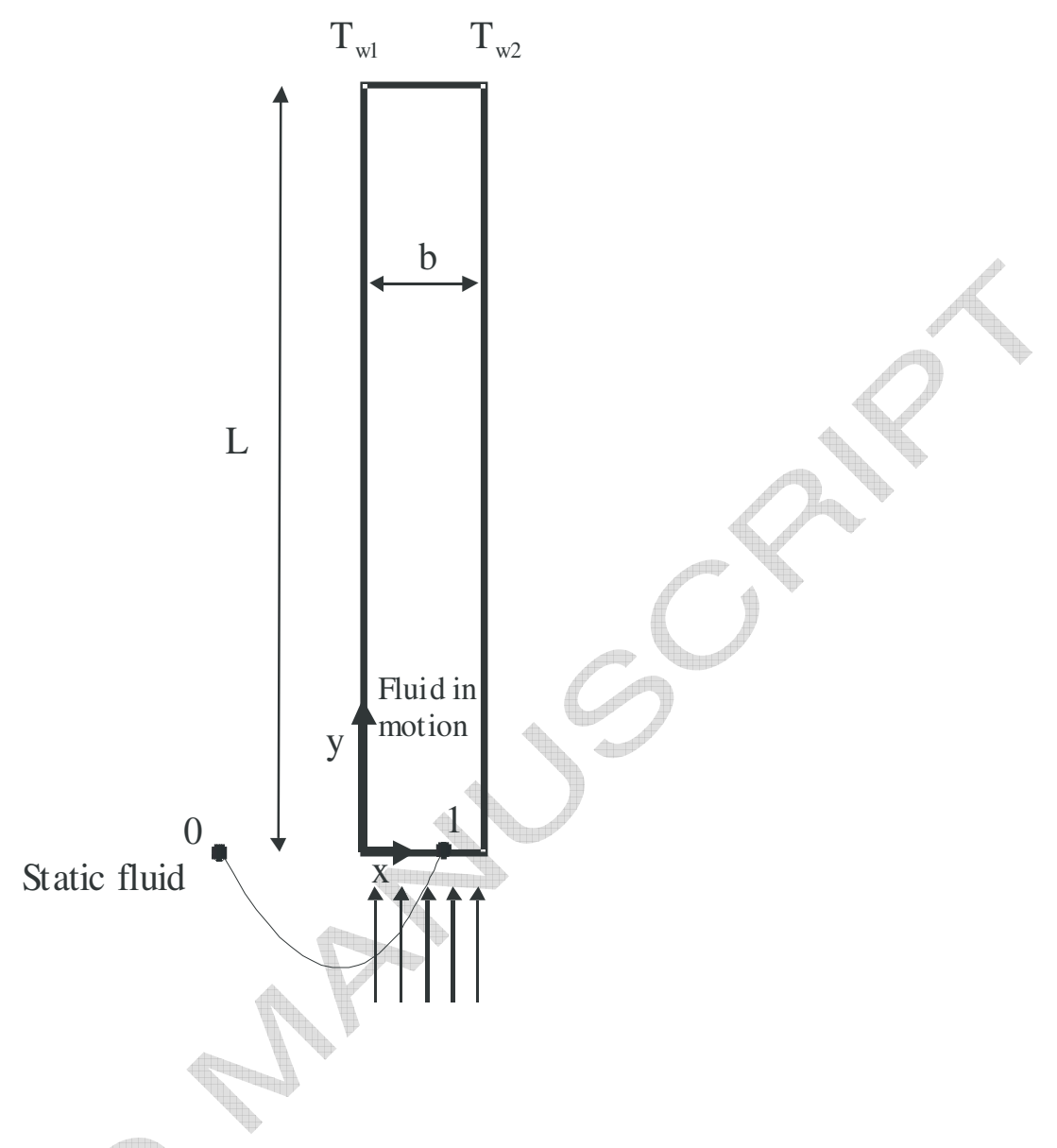

Fig. 2. The geometry studied. 


\section{ACCEPTED MANUSCRIPT}

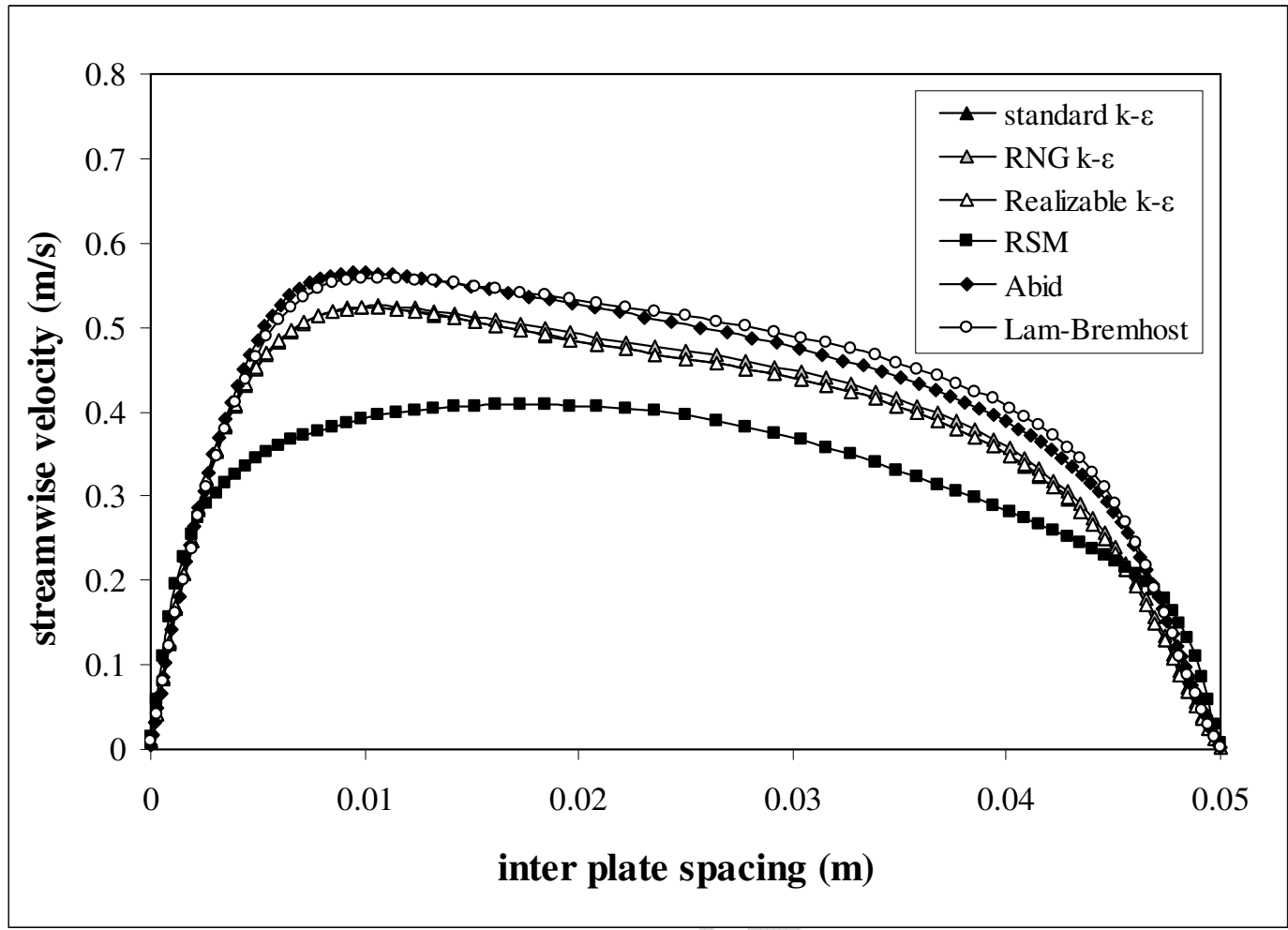

Fig. 3a. Streamwise velocity profile vs inter plate spacing at the chimney outlet for various turbulence models. 


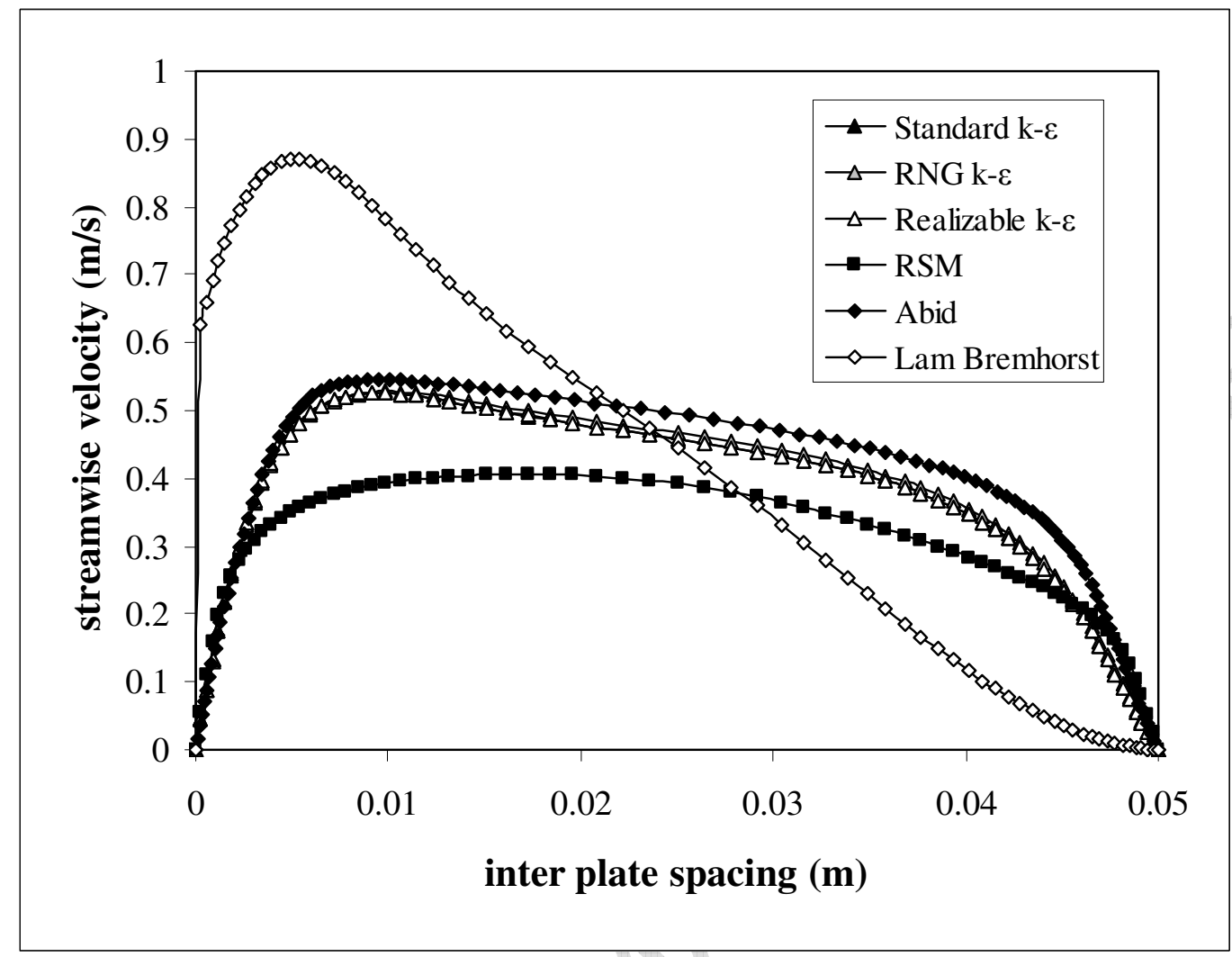

Fig. 3b. Streamwise velocity profile vs inter plate spacing at the middle of the chimney for various turbulence models. 


\section{ACCEPTED MANUSCRIPT}

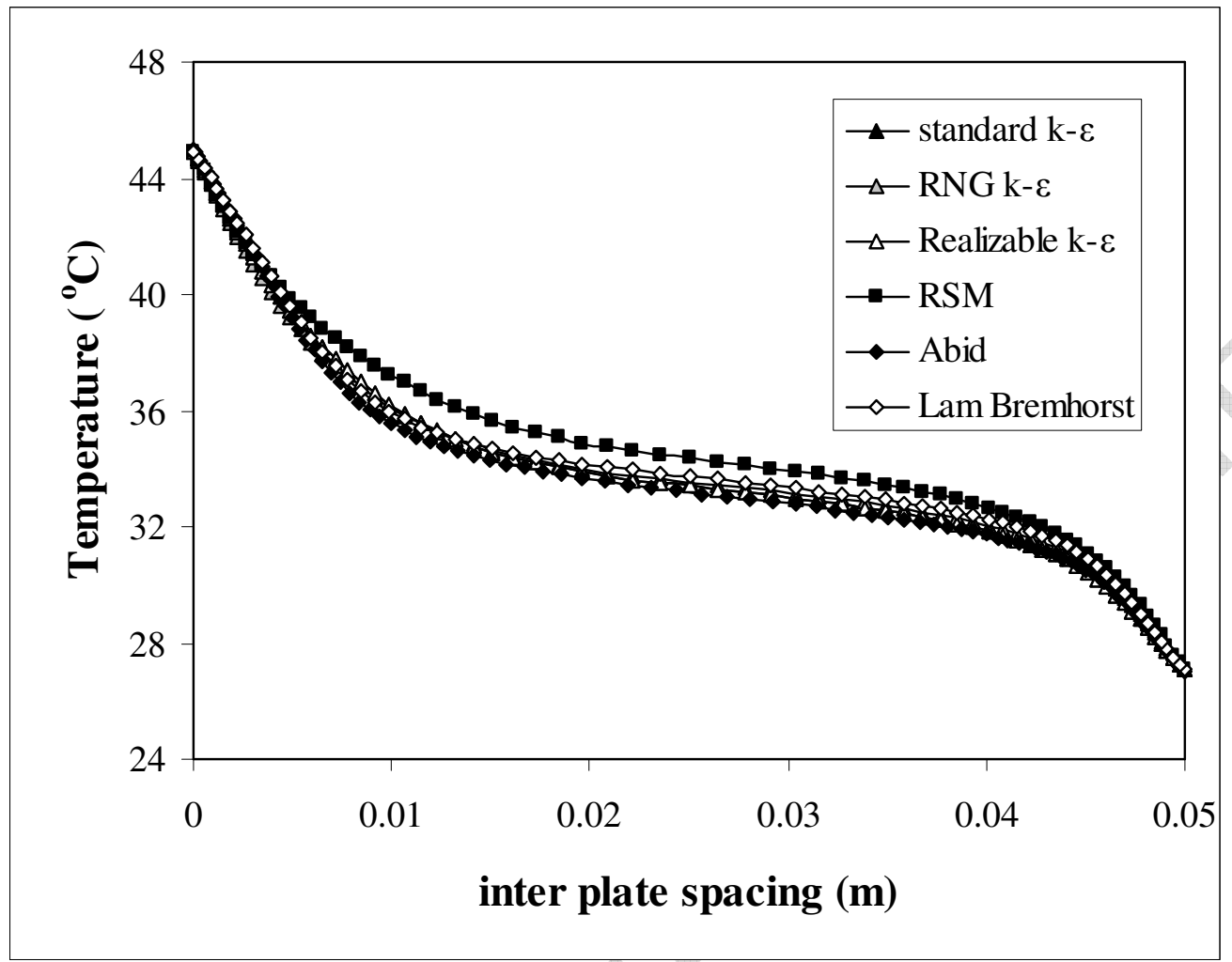

Fig. 4a. Temperature profile vs inter plate spacing at the outlet of the chimney for various turbulence models. 


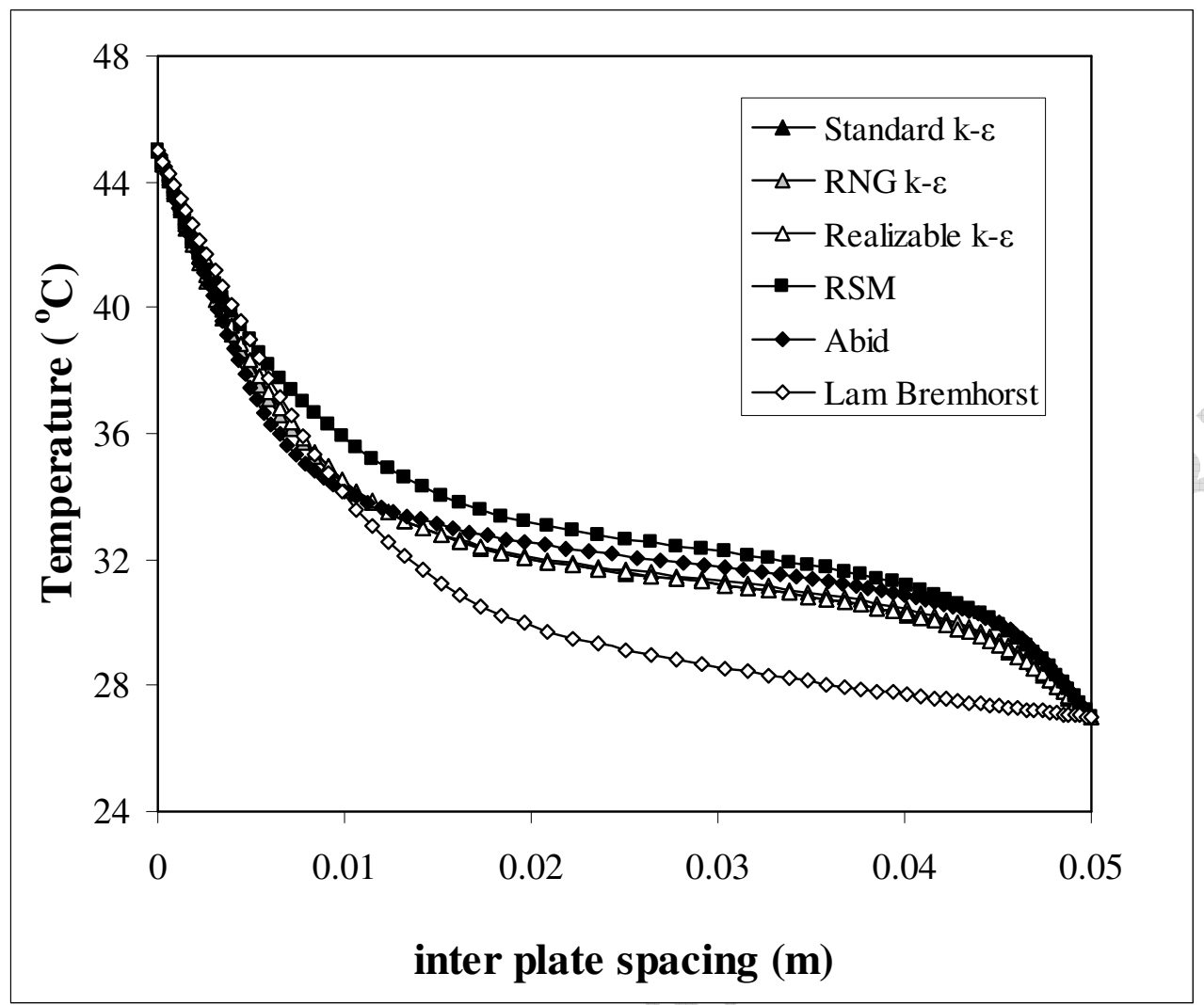

Fig. 4b. Temperature profile vs inter plate spacing at the middle of the chimney for various turbulence models. 


\section{ACCEPTED MANUSCRIPT}

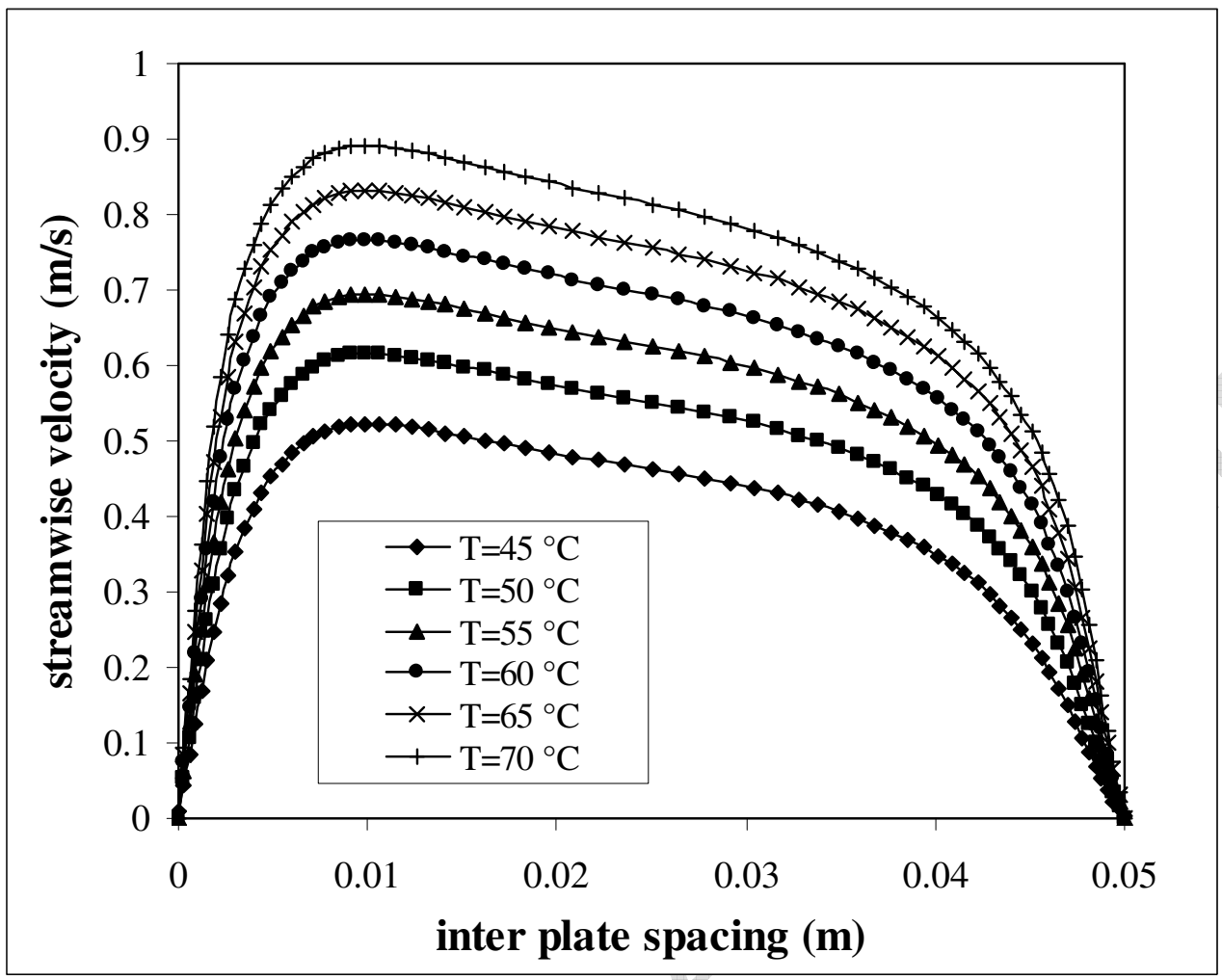

Fig. 5. Predicted streamwise velocity profiles at the outlet of the solar chimney for various temperatures of the left wall. 


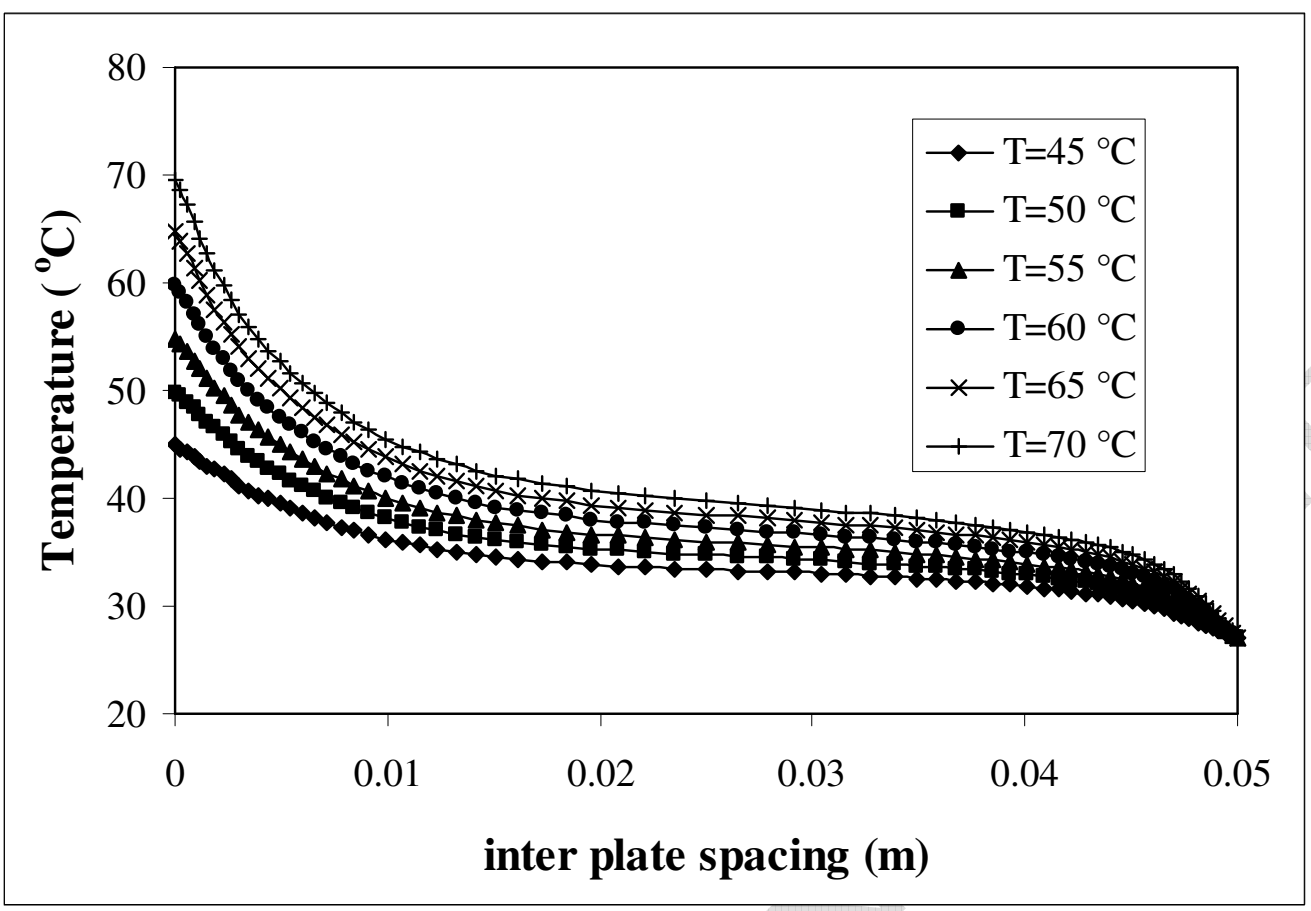

Fig. 6. Predicted temperature profiles at the outlet of the solar chimney for various temperatures of the left wall. 


\section{ACCEPTED MANUSCRIPT}

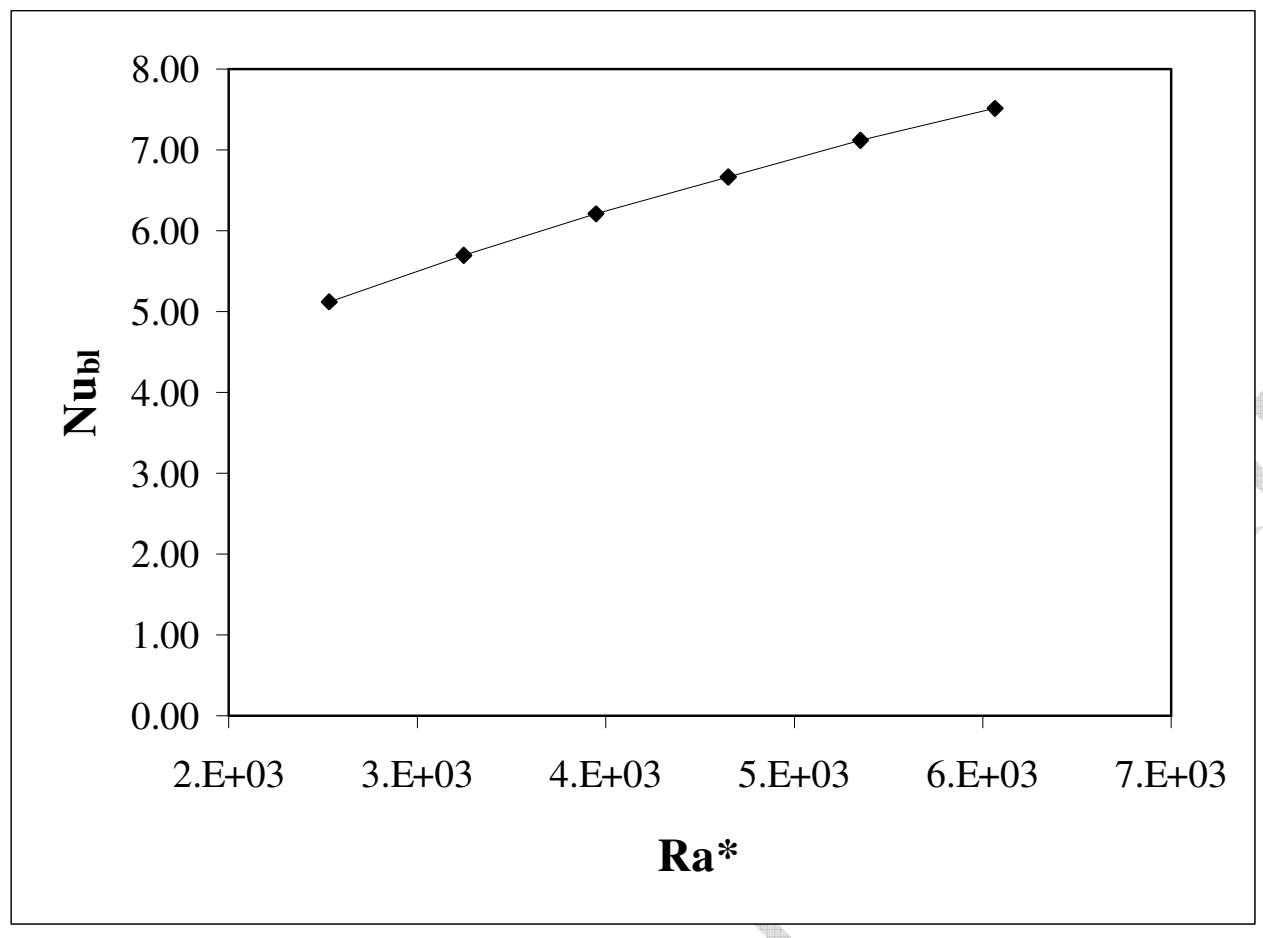

Fig.7. Predicted average $\mathrm{Nu}_{\mathrm{bl}}$ number for the left wall vs. Modified Rayleigh number. 


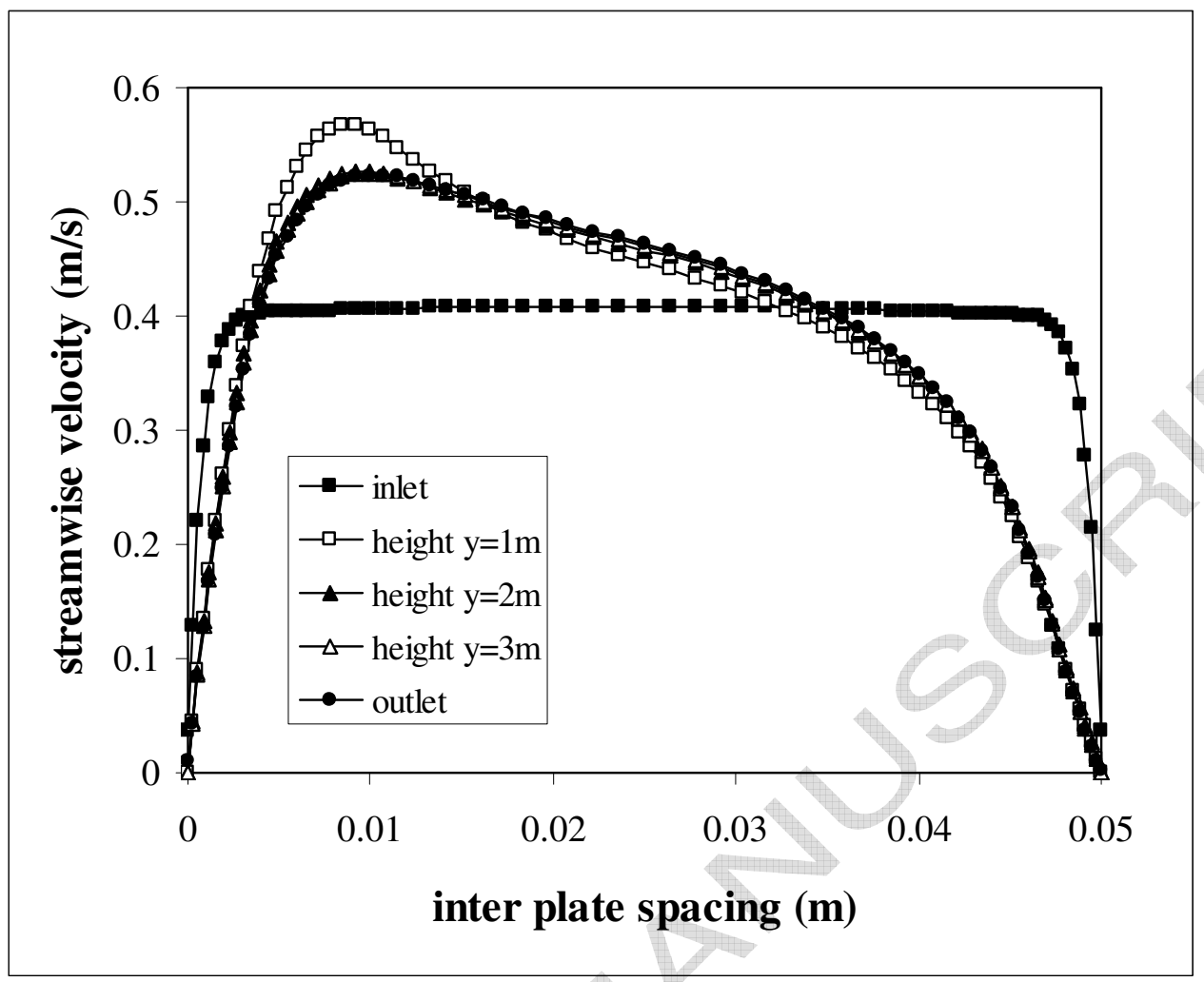

Fig.8. Predicted streamwise velocity profiles across the solar chimney height. 


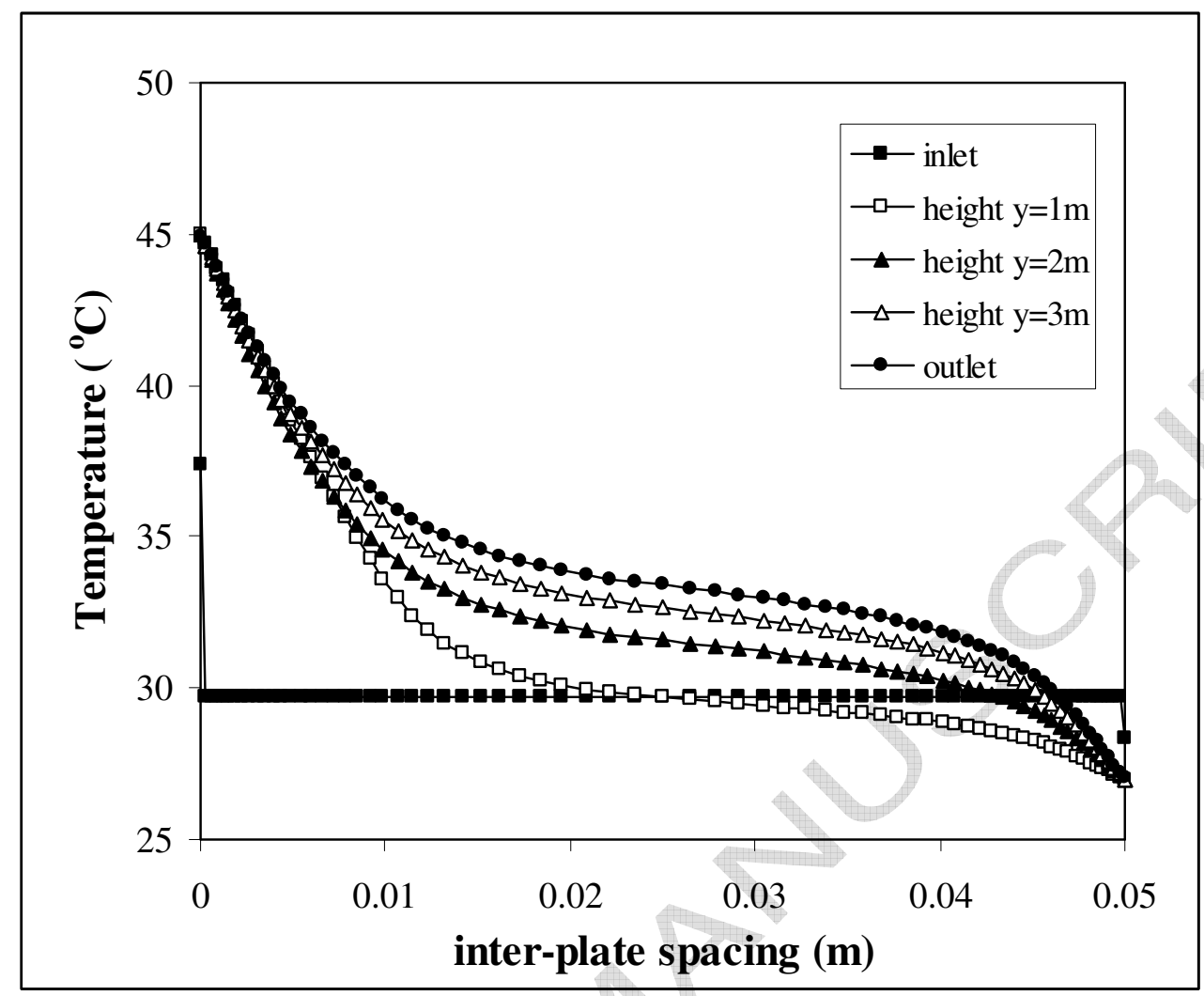

Fig.9. Predicted temperature profiles across the solar chimney height. 


\section{ACCEPTED MANUSCRIPT}

\section{LIST OF TABLES}

Table 1 Average Nusselt number $\mathrm{Nu}_{\mathrm{b}}$ for different grids and different turbulent models.

Table 2 Average Nusselt number for the various turbulence models used.

Table 3 Experimental and predicted average velocity and temperature for the various turbulence models used at the outlet of the wall solar chimney.

Table 4. Predicted mass flow rates and average $\mathrm{Nu}$ numbers for left and right walls of the solar chimney vs. Left wall temperature. 


\section{ACCEPTED MANUSCRIPT}

Table 1 Average Nusselt number $\mathrm{Nu}_{\mathrm{b}}$ for different grids and different turbulent models.

\begin{tabular}{|c|c|c|c|c|c|}
\hline \multicolumn{6}{|c|}{ Standard k- $\varepsilon$} \\
\hline \multicolumn{2}{|c|}{$\mathrm{V} / \mathrm{H}=6$} & \multicolumn{2}{|c|}{$\mathrm{V} / \mathbf{H}=\mathbf{1 0}$} & \multicolumn{2}{|c|}{$\mathrm{V} / \mathrm{H}=\mathbf{2}$} \\
\hline $70 \times 420$ & 5.12 & $70 \times 700$ & 5.12 & $70 \times 140$ & 5.16 \\
\hline $105 \times 630$ & 5.11 & $105 \times 1050$ & 5.10 & $105 \times 210$ & 5.14 \\
\hline $140 \times 840$ & 5.11 & $140 \times 1400$ & 5.10 & $140 \times 280$ & \\
\hline \multicolumn{6}{|c|}{ RNG k- $\varepsilon$} \\
\hline \multicolumn{2}{|c|}{$\mathrm{V} / \mathrm{H}=6$} & \multicolumn{2}{|c|}{$\mathrm{V} / \mathrm{H}=\mathbf{1 0}$} & \multicolumn{2}{|c|}{$\mathrm{V} / \mathrm{H}=\mathbf{2}$} \\
\hline $70 \times 420$ & 5.35 & $70 \times 700$ & 5.34 & $70 \times 140$ & 5.38 \\
\hline $105 \times 630$ & 5.34 & $105 \times 1050$ & - & $105 \times 210$ & - \\
\hline $140 \times 840$ & 5.33 & $140 \times 1400$ & - & $140 \times 280$ & - \\
\hline \multicolumn{6}{|c|}{ Realizable k- $\varepsilon$} \\
\hline \multicolumn{2}{|c|}{$\mathrm{V} / \mathrm{H}=6$} & \multicolumn{2}{|c|}{$\mathrm{V} / \mathrm{H}=\mathbf{1 0}$} & \multicolumn{2}{|c|}{$\mathrm{V} / \mathrm{H}=2$} \\
\hline $70 \times 420$ & 5.13 & $70 \times 700$ & 5.12 & $70 \times 140$ & 5.16 \\
\hline $105 \times 630$ & 5.12 & $105 \times 1050$ & - & $105 \times 210$ & - \\
\hline $140 \times 840$ & 5.11 & $140 \times 1400$ & - & $140 \times 280$ & - \\
\hline \multicolumn{6}{|c|}{ RSM } \\
\hline \multicolumn{2}{|c|}{$V / H=6$} & \multicolumn{2}{|c|}{$\mathrm{V} / \mathrm{H}=\mathbf{1 0}$} & \multicolumn{2}{|c|}{$\mathrm{V} / \mathrm{H}=\mathbf{2}$} \\
\hline $70 \times 420$ & 5.56 & $70 \times 700$ & 5.56 & $70 \times 140$ & 5.59 \\
\hline $105 \times 630$ & 5.57 & $105 \times 1050$ & - & $105 \times 210$ & - \\
\hline $140 \times 840$ & - & $140 \times 1400$ & $-\quad$ & $140 \times 280$ & - \\
\hline \multicolumn{6}{|c|}{ Abid } \\
\hline \multicolumn{2}{|c|}{$V / H=6$} & \multicolumn{2}{|c|}{$\mathrm{V} / \mathrm{H}=\mathbf{1 0}$} & \multicolumn{2}{|c|}{$\mathrm{V} / \mathrm{H}=\mathbf{2}$} \\
\hline $70 \times 420$ & - & $70 \times 700$ & - & $70 \times 140$ & - \\
\hline $105 \times 630$ & 5.30 & $105 \times 1050$ & 5.29 & $105 \times 210$ & - \\
\hline $140 \times 840$ & 5.34 & $140 \times 1400$ & - & $140 \times 280$ & - \\
\hline \multicolumn{6}{|c|}{ Lam-Bremhost } \\
\hline \multicolumn{2}{|c|}{$V / H=6$} & \multicolumn{2}{|c|}{$\mathrm{V} / \mathrm{H}=\mathbf{1 0}$} & \multicolumn{2}{|c|}{$\mathrm{V} / \mathrm{H}=2$} \\
\hline $70 \times 420$ & 5.51 & $70 \times 700$ & - & $70 \times 140$ & - \\
\hline $105 \times 630$ & 5.63 & $105 \times 1050$ & - & $105 \times 210$ & - \\
\hline $140 \times 840$ & 5.69 & $140 \times 1400$ & - & $140 \times 280$ & - \\
\hline
\end{tabular}




\section{ACCEPTED MANUSCRIPT}

Table 2 Average Nusselt number for the various turbulence models used.

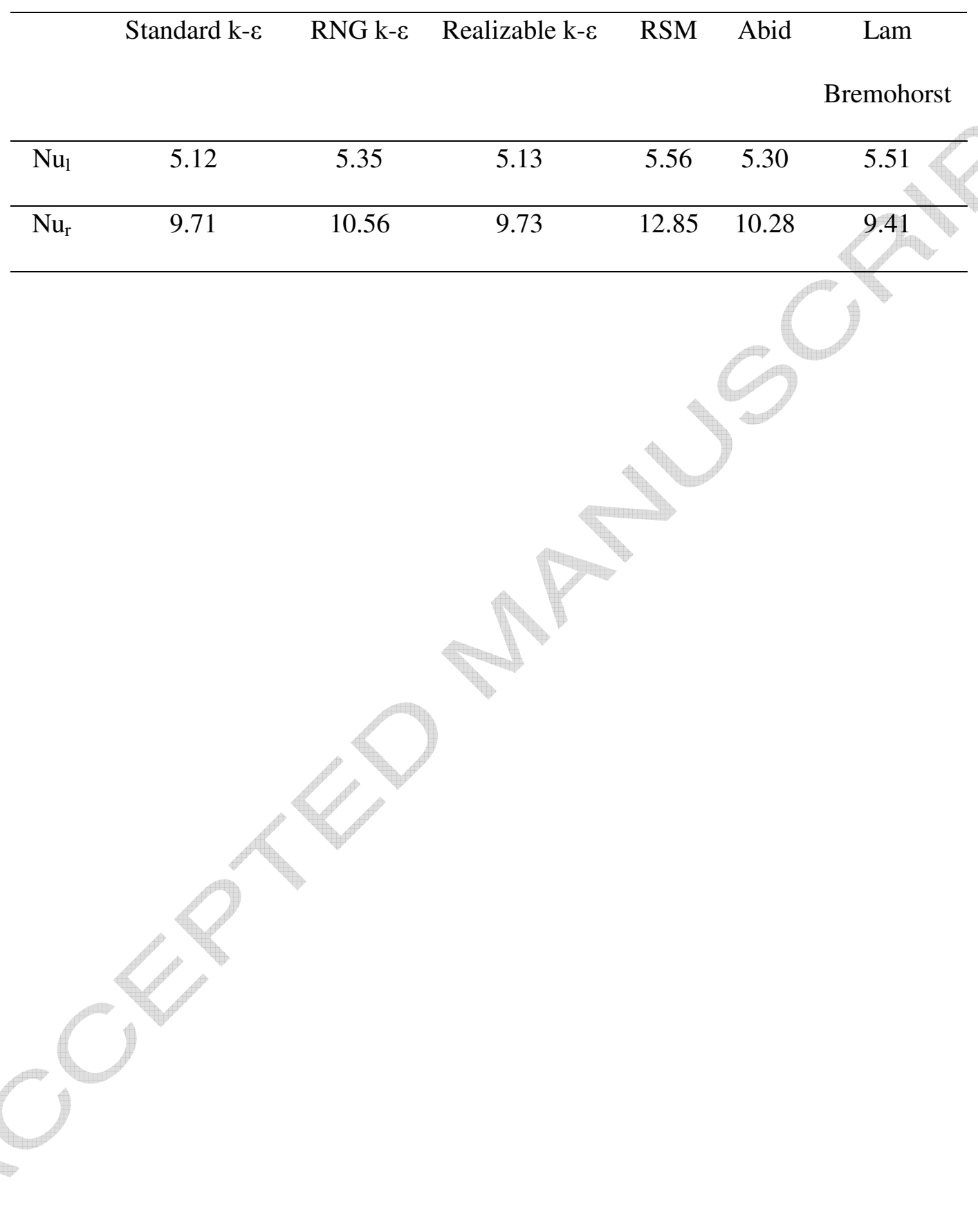


Table 3 Experimental and predicted average velocity and temperature for the various turbulence models used at the outlet of the wall solar chimney.

Inlet air temperature $=29.7^{\circ} \mathrm{C}, \mathrm{T}_{\mathrm{w} 1}=45^{\circ} \mathrm{C}, \mathrm{T}_{\mathrm{w} 2}=27^{\circ} \mathrm{C}$.

\begin{tabular}{cccccccc}
\hline & $\begin{array}{c}\text { Standard } \\
\mathbf{k - \varepsilon}\end{array}$ & $\begin{array}{c}\text { RNG } \\
\mathbf{k - \varepsilon}\end{array}$ & $\begin{array}{c}\text { Realizable } \\
\mathbf{k - \varepsilon}\end{array}$ & RSM & Abid & $\begin{array}{c}\text { Lam } \\
\text { Bremhorst }\end{array}$ & Experimental \\
\hline $\begin{array}{c}\text { Average } \\
\text { velocity }\end{array}$ & 0.3395 & 0.3438 & 0.3395 & 0.2893 & 0.3322 & 0.3731 & 0.3381 \\
\hline $\begin{array}{c}\text { Temperature } \\
\text { at the } \\
\text { middle of } \\
\text { the profile } \\
\left({ }^{\circ} \mathrm{C}\right)\end{array}$ & 33.55 & 33.68 & 33.55 & 34.50 & 33.30 & 33.88 & 32.05 \\
\hline
\end{tabular}


Table 4. Predicted mass flow rates and average Nu numbers for left and right walls of the solar chimney vs. Left wall temperature.

\begin{tabular}{ccccccc}
\hline $\mathbf{T}$ & $\mathbf{4 5}^{\mathbf{}} \mathbf{C}$ & $\mathbf{5 0}^{\mathbf{9}} \mathbf{C}$ & $\mathbf{5 5}^{\mathbf{C}} \mathbf{C}$ & $\mathbf{6 0}^{\mathbf{}} \mathbf{C}$ & $\mathbf{6 5}^{\mathbf{0}} \mathbf{C}$ & $\mathbf{7 0}^{\mathbf{0}} \mathbf{C}$ \\
\hline$\dot{\mathrm{m}}(\mathbf{k g} / \mathbf{s})$ & 0.02298 & 0.02763 & 0.03161 & 0.03524 & 0.03856 & 0.04165 \\
\hline $\mathbf{N u}$ & & & & & & \\
\hline $\mathbf{N u}$ & 5.13 & 5.69 & 6.20 & 6.67 & 7.11 & 7.51 \\
\hline $\mathbf{N u r}$ & 9.73 & 11.92 & 14.05 & 16.29 & 18.57 & 20.89 \\
\hline
\end{tabular}

